www.jmscr.igmpublication.org Impact Factor 5.84

Index Copernicus Value: 71.58

ISSN (e)-2347-176x ISSN (p) 2455-0450

crossref DOI: _https://dx.doi.org/10.18535/jmscr/v5i10.167

Journal Of Medical Science And Clinical Research

IGM Publication

An Official Publication of IGM Publication

\title{
Original Article \\ Prescription Pattern in Patients of Acute Coronary Syndrome in a Rural Tertiary Care Centre of Maharashtra
}

\author{
Authors \\ Dr S P Narwane ${ }^{1}$, Dr A P Marawar ${ }^{* 2}$, Ms. Shah J3 $\mathbf{3}^{3}$ Dr Sayed Asif Umar ${ }^{4}$ \\ ${ }^{1}$ Assistant Professor, Department of Pharmacology, Rural Medical College, PIMS (DU), Loni (BK), \\ Tal- Rahata, Dist- Ahmednagar, Maharashtra, India Pin code-413736 \\ Email: drsandeepnarwane1984@ gmail.com \\ ${ }^{2}$ Department of Pharmacology, Rural Medical College, PIMS (DU), Loni (BK), Tal- Rahata, Dist- \\ Ahmednagar, Maharashtra, India. Pin code-413736 \\ Email:annu777@gmail.com \\ ${ }^{3}$ III year MBBS Student, Rural Medical College, PIMS (DU), Loni (BK), Tal- Rahata, Dist- Ahmednagar, \\ Maharashtra, India Pin code-413736 \\ Email: jainishah95@yahoo.com \\ ${ }^{4}$ Assistant Professor, Department of Pharmacology PMT-PIMS
}

\begin{abstract}
In the present study prescribing pattern of various drugs prescribed in Acute Coronary Syndromes (ACS) was studied. It was a retrospective, observational study in the Department of Pharmacology and Medicine from June to May 2017. The data from Record Department from 2011 to 2015. Prescribing patterns of various drugs prescribed in ACS were analyzed. 600 complete records of patients admitted for ACS were included in the study, of which 483 (80.5\%) were of male patients and 117 (19.5\%) were of female patients. Hypertension (39\%) and diabetes (6.8\%) were the most common co-morbid conditions associated with ACS. The most commonly prescribed drug classes for main indications in Acute Coronary Syndrome were anti-platelet drugs 600 (100\%) followed by antihypertensives (96.16\%) and antihyperlipidemics (91.16\%). Extensive polypharmacy (9.68 drugs per prescription) was noticed in the prescriptions. The prescribing pattern can be improved by reducing the number of drugs per prescription. Many drugs were prescribed by generic name (61\%). The economic burden of the patients can be reduced by prescribing more generic drugs.

Keywords: Prescription pattern, Acute coronary syndrome, Observational Study, Polypharmacy.
\end{abstract}

\section{Introduction}

The term Acute Coronary Syndrome (ACS) includes group of clinical symptoms due to acute myocardial ischemia and includes unstable angina (UA), non-ST-segment elevation myocardial infarction (NSTEMI), and ST-segment elevation myocardial infarction (STEMI). These are acute manifestations of Coronary Artery Disease (CAD). Annually, approximately 1.36 million hospitalizations for ACS occur in United States, of which 0.81 million are for myocardial infarction (MI). ${ }^{1}$ In a 2014 study using World 
Health Organization (WHO) data from 49 countries in Europe and northern Asia, over 4 million annual deaths were due to Coronary Heart Disease $(\mathrm{CHD})^{2}$

Mortality from CHD is expected to increase in developing countries like India, from an estimated 9 million in 1990 to a projected 19 million by $2020^{3,4}$. CAD has emerged as an epidemic in India. The mortality \& morbidity from CAD among Asian Indians is reported to be higher than among Americans, Europeans, and other Asians, irrespective of their present residence ${ }^{5}$ ACS is treated pharmacologically by Nitroglycerine, in the form of either sublingual tablet or spray, followed by intravenous administration for all patients Morphine sulfate, intravenously for patients who have symptoms that are not immediately relieved with nitroglycerin. It is also given in patients who have acute congestion of lung, severe agitation, or both. Intravenous $\beta$ Blocker followed by oral administration (if not contraindicated) is given for patients with prolonged chest pain. Nondihydropyridine Calcium Channel Blockers is given as initial therapy in the absence of contraindications for patients with continuing or frequently recurring ischemia and $\beta$-blockers are contraindicated. ACE inhibitor is used in patients with hypertension, when not controlled with nitroglycerin and a $\beta$ blocker. ACE inhibitors are also indicated in presence of LV systolic dysfunction, CHF with diabetes ${ }^{6}$.

It has been hypothesized that when collectively, these agents could reduce long term risk of complications and mortality by as much as $75 \%{ }^{7}$. The actual impact, however, depends on the extent to which they are used in practice ${ }^{8-10}$.

Irrational prescribing of drugs is of common occurrence in clinical practice ${ }^{11}$, and result in ineffective and unsafe treatment, prolongation of illness, distress and unnecessary economic burden to the patient ${ }^{12}$. Studies of prescribing patterns and drug utilization are useful to identify the problems and provide feedback to prescribers so as to create awareness about rational use of $\operatorname{drugs}^{13}$.
Therefore, this study was an attempt to analyze the current prescription patterns of drugs used in the treatment of Acute Coronary Syndromein order to ensure appropriate drug use to reduce the morbidity and mortality of the disease and reduce the unnecessary economic burden on the patient.

\section{Objective}

To analyze the current prescription patterns of drugs used in the treatment of Acute Coronary Syndrome Patients admitted in Pravara Rural Hospital, Loni.

\section{Methodology}

This was a retrospective cross sectional observational study carried out in collaboration with Department of Medicine, PRH, Loni from June to May 2017. Approval of Institutional Ethics Committee, PIMS, Loni was taken proir to initiation of study. Complete records of the patients admitted in Medicine department of PRH, Loni during the period of 2011 to 2015 were studied. Complete medical records of all patients of both sex with age 18 and above who were diagnosed and admitted in Pravara Rural Hospital, Loni with Acute Coronary Syndrome were included in the study. Patients who were under day care management and those who were diagnosed with other cardiac diseases were excluded from the study.

\section{Data Collection}

The data were collected from the patient's records who met the inclusion and exclusion criteria. Relevand data of every in-patient with Acute Coronary Syndrome were collected in a well structured data collection form. The demographic data, the diagnosis and the relevant data on drug prescription of each patient were obtained from the in-patient case records of each patient.

Study procedure: Complete Prescriptions of 600 patients admitted with acute coronary syndromes were analyzed as per WHO guidelines in regards to sample size calculation for such studies ${ }^{14}$. The data collected and recorded in the data collection form included the demographic details (age, sex), 
drugs (name of the drug, dosage form, dose, route of administration, frequency), principal diagnosis and co-morbid conditions of each patient.

The trade names of drugs were decoded and categorized into pharmacological classes. Utilization of different classes of drugs as well as individual drugs was analyzed and presented as percentage. The average number of drugs per prescription and the percentage of drugs prescribed by generic name were determined. The percentage encounters with an antibiotic prescribed was also determined ${ }^{14}$.

\section{Results}

A total number of 600 prescriptions of patients admitted for acute coronary syndromes during the period of 2011-15 were studied, in which 483 (80.5\%) were of male patients and 117 (19.5\%) were of female patients. The male to female ratio was 4:1. Mean age of the patients was $56.94 \pm 11.98$ years.

$402(67 \%)$ patients were admitted with diagnosis of Myocardial Infarction, while 198 (33\%) were diagnosed as Angina. Hypertension and Diabetes were the two commonly occuring co-morbid conditions. Other associated comorbic conditions were COPD and Peripheral Vascular disease. Patients also presented with cardiac complications like heart block, arrhythmias, congestive cardiac failure and cardiogenic shock (Table 1).

Table no. 1: Distribution of the patients according to co-morbid conditions and complications

\begin{tabular}{|l|c|c|}
\hline $\begin{array}{l}\text { Co-morbid condition/ } \\
\text { Complication }\end{array}$ & $\begin{array}{c}\text { No. of } \\
\text { patients (600) }\end{array}$ & Percentage \\
\hline Hypertention & 235 & 39.1 \\
\hline Type 2 Diabetes Mellitus & 41 & 6.8 \\
\hline COPD IHD, & 15 & 2.5 \\
\hline $\begin{array}{l}\text { Cardiac complications } \\
\text { Arrhythmias, } \begin{array}{l}\text { Cardiogenic shock, CCF) } \\
\text { PVD }\end{array}\end{array}$ & 8.2 \\
\hline Others & 07 & 1 \\
\hline Total & 415 & 69.1 \\
\hline
\end{tabular}

Of all the patients, $217(36.2 \%)$ were having history of addiction in the form of Alcohol, Tobacco or both (Table 2).
Table no. 2: Addictive habits among the patients

\begin{tabular}{|l|c|c|}
\hline $\begin{array}{l}\text { Significant History/ } \\
\text { addictive habits }\end{array}$ & $\begin{array}{c}\text { No. of patients } \\
(\mathrm{n}=600)\end{array}$ & Percentage \\
\hline $\begin{array}{l}\text { Habit of Chronic alcohol } \\
\text { consumption }\end{array}$ & 20 & 3.3 \\
\hline $\begin{array}{l}\text { Habit of Tobacco } \\
\text { (chewing/ smoking) }\end{array}$ & 129 & 21.5 \\
\hline $\begin{array}{l}\text { Habit of alcohol and } \\
\text { tobacco use }\end{array}$ & 68 & 11.1 \\
\hline Total & 217 & 36.2 \\
\hline
\end{tabular}

Acute Coronary Syndrometreatment involves various categories of drugs namely antiplatelet drugs, antihyperlipidemic agents, antibiotics, antianginal drugs, antihypertensives, anticoagulants, bronchodilators, fibrinolytics, etc. The usages of these drugs were recorded and analyzed as shown in table no.3. Among these drugs antiplatelets were given to all the patients. Antihypertensives were used in almost 577(96.16\%) patients and next to that antihyperlipidemics were prescribed to $547(91.16 \%)$ patients. Vitamins were least used only in $36(6 \%)$ patients.

Table no. 3: Usage of the drugs in the treatment of Acute Coronary Syndrome

\begin{tabular}{|l|c|c|}
\hline Drug classes & $\begin{array}{c}\text { No. of prescriptions } \\
(\mathrm{N}=600)\end{array}$ & Percentage \\
\hline Antiplatelets & 600 & 100 \\
\hline Antihyperlipidemic & 547 & 91.16 \\
\hline Antibiotics & 29 & 4.83 \\
\hline Anti-anginal & 222 & 37 \\
\hline Antihypertensives & 577 & 96.16 \\
\hline Anticoagulants & 520 & 41.66 \\
\hline Bronchodilators & 11 & 1.83 \\
\hline Benzodiazepines & 524 & 87.33 \\
\hline Antacids & 531 & 88.5 \\
\hline Antidiabetics & 96 & 16 \\
\hline Fibrinolytic & 402 & 67 \\
\hline Vitamins & 36 & 6 \\
\hline Adrenergic & 63 & 10.5 \\
\hline Analgesic & 181 & 30.16 \\
\hline Laxative & 275 & 45.83 \\
\hline Antiemetics & 468 & 78 \\
\hline Others & 73 & 12.16 \\
\hline
\end{tabular}

The anti-platelet drugs, clopidogrel and aspirin were used to reduce the cardiovascular mortality and non- fatal myocardial infarction in coronary artery disease. Among 600 prescriptions analyzed anti-platelet drugs were prescribed in all the 600 (100\%) patients. Details of anti-platelet drugs prescribed are shown in table 4 . Out of these, 
majority of the patients i.e. $481(80.16 \%)$ patients were prescribed with clopidogrel and aspirin. Fixed dose combination of Clopidogrel and aspirin was used in 68(11.33\%) patients. Aspirin alone was prescribed to only $51(8.5 \%)$ patients. All these drugs were prescribed in oral dosage form.

Table no. 4: Antiplatelet drugs prescribed for the treatment of Acute Coronary Syndrome

\begin{tabular}{|l|c|c|}
\hline Antiplatelets & $\begin{array}{c}\text { No of Prescriptions } \\
(\mathrm{n}=600)\end{array}$ & $\begin{array}{c}\text { Percentage } \\
(\%)\end{array}$ \\
\hline Aspirin & 51 & 8.5 \\
\hline $\begin{array}{l}\text { Aspirin } \\
\text { Clopidogrel }\end{array}$ & 481 & 80.16 \\
\hline $\begin{array}{l}\text { Aspirin + Clopidogrel } \\
\text { combination }\end{array}$ & 68 & 11.33 \\
\hline
\end{tabular}

Table no. 5 gives the details of antihyperlipidemic drugs prescribed for the treatment of coronary artery disease. Among the antihyperlipidemic drugs, commonly prescribed was Atorvastatin in 516(94.33\%) patients while the Fenofibrate was least used in only $3(0.54 \%)$ patients.

Table no. 5: Antihyperlipidemic drugs prescribed for the treatment of Acute Coronary Syndrome

\begin{tabular}{|l|c|c|}
\hline Antihyperlipidemic & $\begin{array}{c}\text { No of Prescriptions } \\
(547)\end{array}$ & Percentage (\%) \\
\hline Atorvastatin & 516 & 94.33 \\
\hline Rosuvastatin & 24 & 4.38 \\
\hline Combination & 4 & 0.73 \\
\hline Fenofibrate & 3 & 0.54 \\
\hline
\end{tabular}

Only $29(4.83 \%)$ patients were prescribed with antibiotics like amikacin(13.79\%), Amoxicillin+ Clavilunic Acid (27.58\%), Albendazole(6.89\%), Clotrimoxazole(20.68\%), Amoxicillin(20.68\%), Fluconazole(10.34\%) as shown in table no.6.

Table no. 6: Antibiotics drugs prescribed for the treatment of Acute Coronary Syndrome

\begin{tabular}{|l|c|c|}
\hline Antibiotics & $\begin{array}{c}\text { No. of } \\
\text { prescriptions (29) }\end{array}$ & Percentages \\
\hline Amikacin & 4 & 13.79 \\
\hline $\begin{array}{l}\text { Amoxicillin+Clavilunic } \\
\text { acid }\end{array}$ & 8 & 27.58 \\
\hline Albendazole & 2 & 6.89 \\
\hline Clotrimoxazole & 6 & 20.68 \\
\hline Amoxicillin & 6 & 20.68 \\
\hline Fluconazole & 3 & 10.34 \\
\hline
\end{tabular}

Various antianginal drugs like vasodilators isosorbide, NTG, nicorandil were used in $222(37 \%)$ patients as shown in table no. 7.

Table no. 7: Anti-anginal drugs prescribed for the treatment of Acute Coronary Syndrome

\begin{tabular}{|l|c|c|}
\hline $\begin{array}{l}\text { Anti-anginal } \\
\text { drugs }\end{array}$ & $\begin{array}{c}\text { No. of prescriptions } \\
(\mathrm{n}=222)\end{array}$ & Percentage \\
\hline Isosorbide & 21 & 9.45 \\
\hline Nitroglycerine & 192 & 86.48 \\
\hline Nicorandil & 9 & 4.05 \\
\hline
\end{tabular}

Out of 600 patients, among 235 patients hypertention was found as comorbid condition and hypertensives were prescribed in $96.16 \%$ patients as shown in table no. 8. The antihypertensives used were CCB (Amlodepin) in 0.69\%; Beta blockers in $53.89 \%$ patients; $\mathrm{MgSO} 4$ in $1.21 \%$ patients; drugs acting on Renin Angiotensin system were used in $145(25.12 \%)$ patients; Diuretics in $110(19.06 \%)$ patients.

Table no. 8: Antihypertensives drugs prescribed for the treatment of Acute Coronary Syndrome

\begin{tabular}{|l|c|c|}
\hline Antihypertensives drugs & $\begin{array}{c}\text { No. of } \\
\text { prescriptions (n= } \\
577)\end{array}$ & Percentage \\
\hline CCB & 4 & 0.69 \\
Amlodipine & 311 & \\
\hline Beta Blockers & 3 & 53.89 \\
Propranolol & 103 & \\
Ismolol & 205 & \\
Metoprolol & 7 & 1.21 \\
\hline MgSO4 & 145 & 25.12 \\
\hline Drugs acting on Renin & 9 & \\
Angiotensin System & 136 & \\
Telmisartan & 110 & \\
Ramipril & 104 & \\
\hline Diuretics & 3 & \\
Furosemide & 3 & \\
Chlordiazepoxide & & \\
Combination & & \\
\hline
\end{tabular}

The anticoagulants in the form of low molecular weight heparin i.e, enoxaparine was prescribed in $520(41.66 \%)$ prescriptions.

Benzodiazepines were prescribed in the form of alprazolam, clonazepam, diazepam to 524 $(87.33 \%)$ patients (Table 9$)$ 
Table no. 9: Benzodiazepines prescribed for the treatment of Acute Coronary Syndrome

\begin{tabular}{|l|c|c|}
\hline Benzodiazepines & $\begin{array}{c}\text { No. of prescriptions } \\
(\mathrm{n}=524)\end{array}$ & Percentage \\
\hline Alprazolam & 492 & 93.89 \\
\hline Clonazepam & 4 & 0.76 \\
\hline Diazepam & 28 & 5.34 \\
\hline
\end{tabular}

Almost 531(88.5\%) patients received antacids in the form of pantoprazole, ranitidine, esomeprazole, omeprazole. Out of 600 patients, $96(16 \%)$ patients suffered from diabetes mellitus and received antidiabetics either injectable insulin $84(87.5 \%)$ or oral Metformin 12(12.5\%).

Table no. 10 shows the adrenergic drugs prescribed for the treatment of acute coronary syndrome. It included adrenaline in $4.76 \%$ patients, noradrenaline in $23.8 \%$, dopamine in $50.79 \%$ and dubutamine in $20.63 \%$ patients.

Table no. 11: Adrenergic prescribed for the treatment of Acute Coronary Syndrome

\begin{tabular}{|l|c|c|}
\hline Adrenergic & No. of prescriptions $(\mathrm{n}=63)$ & Percentage \\
\hline Adrenaline & 3 & 4.76 \\
\hline Nor-adrenaline & 15 & 23.8 \\
\hline Dopamine & 32 & 50.79 \\
\hline Dobutamine & 13 & 20.63 \\
\hline
\end{tabular}

Analgesics were prescribed in 181 (30.16\%) patients. Various analgesics prescribed were buprenorphine, Bupropion, Tramadol, Paracetamol. Laxatives were prescribed to 275 (45.83\%) patients. Fibrinolytic in the form of Streptokinase was prescribed to $402(67 \%)$ patients. Multivitamins were used in $36(6 \%)$ prescriptions, and antiemetics to $468(78 \%)$ patients.

Table no. 11 depicts the other drugs prescribed in the prescriptions. Other drugs included steroids (4.1\%), antiarrythmics (21.91\%), Amiodarone (15.06\%), $\mathrm{KCl}(6.8 \%)$, Anticholinergic (43.83\%), Digoxin $(4.1 \%)$ and Promethazine $(4.1 \%)$.

Table no. 11: Other drugs prescribed for the treatment of Acute Coronary Syndrome

\begin{tabular}{|l|c|c|}
\hline Other drugs & No. of prescriptions $(\mathrm{N}=73)$ & Percentage \\
\hline Steroids & 3 & 4.1 \\
\hline Antiarrhythmics & 16 & 21.91 \\
\hline Amiodarone & 11 & 15.06 \\
\hline $\mathrm{KCl}$ & 5 & 6.8 \\
\hline $\begin{array}{l}\text { Anticholinergic } \\
\text { (Atropine ) }\end{array}$ & 32 & 43.83 \\
\hline Digoxin & 3 & 4.1 \\
\hline Promethazine & 3 & 4.1 \\
\hline
\end{tabular}

The total numbers of 5155 drug were prescribed in 600 prescriptions of the patients, with average of 8.59 drugs per prescription. Out of these drugs, $3146(61.02 \%)$ were prescribed with the generic name while 2009 (38.97\%) were with Brand names. Table no. 12 shows the details of the prescriptions analysed.

Table 12: Summary of Prescriptions for Acute Coronary Syndrome patients treated

\begin{tabular}{|l|c|}
\hline Details of the prescription & Number (\%) \\
\hline $\begin{array}{l}\text { Total number of patient's prescriptions } \\
\text { analysed }\end{array}$ & 600 \\
\hline Total number of drugs prescribed & 5155 \\
\hline Average number of drugs per prescription & 8.59 \\
\hline Number of drugs prescribed by generic name & $3146(61.02)$ \\
\hline Number of drugs prescribed by brand name & $\begin{array}{c}2009 \\
(38.97)\end{array}$ \\
\hline
\end{tabular}

\section{Discussion}

In a study conducted by Kamath $\mathrm{A}$ et al., of the 349 patients, $81 \%$ were males and $19 \%$ females ${ }^{15}$. In a retrospective study conducted by Tasneem Sandozi and Fouzia Nausheen, of the 140 patients studied, 96 of these patients were men and 44 of them were women ${ }^{16}$. In the present study, out of 600 patient's prescriptions, $483(80.5 \%)$ were of male patients and $117(19.5 \%)$ were of female patients. Mean age of the patients was $56.94 \pm 11.98$ years. The results of this study were found to be in consistence with previous studies and indicated that male were more prone to Acute Coronary Syndrome compared to female.

In a study conducted by Tasneem Sandozi and Fouzia Nausheen the drug prescription pattern of various antiplatelet drugs included, aspirin alone $(25.71 \%)$, aspirin \& clopidogrel $(60.00 \%)^{16}$. In the present study, number patient prescribed with aspirin alone was $8.5 \%$ patients, aspirin and clopidogrel were given together in $80.16 \%$ patients, while, $11.33 \%$ patients received fixed dose combination of aspirin and clopidogrel. In the present study the combination of aspirin and clopidogrel were prescribed in more number of patients compared to previous study.

In a study conducted by Jorg Muntwyler, et al., the drug prescription rates of antiplatelet, lipid lowering drugs, beta-blockers and ACE inhibitors/ 
angiotensin receptor blockers were $91 \%, 63 \%$, $58 \%$ and $50 \%$ respectively ${ }^{17}$. In the present study, antiplatelets were given to all the 600 patients i.e. the drug prescription rates of antiplatelets were $100 \%$, lipid lowering drugs were prescribed in $91.16 \%$, beta-blockers in $53.89 \%$ and ACE inhibitors/angiotensin receptor blockers in $25.12 \%$. The prescription rate of lipid lowering drugs in present study were comparatively very high than the previous study.

In the study conducted by Tasneem Sandozi and Fouzia Nausheen, the drug prescription rate for Low molecular weight heparin was $20.00 \%{ }^{16}$. In another study conducted by Banerjee S., et al., unfractionated low molecular weight heparin was used in $25.2 \%^{18}$. In the present study, the prescription rate of low molecular weight heparin was $91.34 \%$. The results of this study are not in consistence with previous studies. A greater variation in the use of anticoagulant was observed. A study conducted by Jorg Muntwyler, et al., observed the drug prescription rates for betablockers, ACE-inhibitors/angiotensin receptor blockers as $58 \%$ and $50 \%$ respectively ${ }^{17}$. In a study conducted by Supratim Datta the overall use of antihypertensives in Acute Coronary Syndromewas as follows, Calcium channel blockers (73\%), Beta blockers (37.2\%), ACEIs $(42.3 \%)^{19}$. In the present study, the use of antihypertensives were as follows calcium channel blockers $0.69 \%$, Beta blockers in $51.83 \%$, ACEIs/angiotensin receptor blockers in $25.12 \%$ patients. The previous study indicated high use of calcium channel blockers, whereas in the present study beta blockers were found to be the preferable choice of antihypertensive prescribed.

In a study conducted by Sreedevi K et al., out of 1000 prescriptions, the different statins prescribed were Atorvastatin in 261 prescriptions, Rosuvastatin in 26 prescriptions ${ }^{20}$. In the study conducted by Tasneem Sandozi and Fouzia Nausheen indicated prescription of lipid lowering drugs to be $68.57 \%^{16}$. In the present study, Atorvastatin was prescribed in 516 prescriptions and rosuvastatin in 24 prescriptions out of 600 prescriptions. The present study recorded the use of lipid lowering drugs as $91.16 \%$. The prescription of antihyperlipidemic drugs was found to be very high in this study compared to earlier studies. But still atorvastatin remains the most common choice for presription among the various statins available to reduce cholesterol levels.

In a study conducted by Banerjee S., et al., the commonly prescribed drugs were as follows isosorbide mononitrate among the nitrates, clopidogrel among the antiplatelet agents, metoprolol among the beta blockers, amlodipine among the Calcium channel blockers, ramipril among the ACE inhibitors, atorvastatin among the hypolipidaemics and unfractionated heparin (UFH) among the anticoagulants ${ }^{18}$. In the present study, the commonly prescribed drugs were NTG among the nitrates, aspirin and clopidogrel among the antiplatelet agents, metoprolol among the beta blockers, amlodipine among the Calcium channel blockers, ramipril among the ACE inhibitors, atorvastatin among the hypolipidaemics and LMWH among the anticoagulants. A variation in prescribing of antiplatelet drugs, anticoagulants was observed.

In all, there was more inclination towards prescription of antiplatelet, anticoagulants, and hypolipidaemics in the patients with acute coronary syndromes. The reason behind this might be more number of patients presenting with Myocardial Infarction (402) as against Angina (198).

In the study conducted by Tasneem sandozi et al., the average number of drugs used per patient was 9.93 which are high. Percentage of drugs prescribed by generic names was $6.00 \%{ }^{16}$. In a study conducted by Sreedevi, et al., the average number of drugs per prescription was found to be 5.5. Rare prescriptions were observed with generic names of the drugs, many prescriptions especially of CVD were containing fixed dose combinations (FDC) ${ }^{20}$. In the present study, the average no. of drugs per patient is 8.59 which are similar to the previous study. The percentage of drugs 
prescribed by generic name is $61.08 \%$. The present and previous studies have not shown much variation in the average number of drugs per prescription. The percentage of drugs used by generic name varied from the previous study. Present study showed a higher rate of prescribing drugs by their generic name. This indicates more inclination of the prescribing doctors to prescribe generic drugs.

The only drawback of the present study was that it was retrospective study, as the data was obtained form records of the patients.

\section{Conclusion}

In this study, it was observed that the risk for Acute Coronary Syndrome was more among males than females. Hypertension and diabetes were the most common co-morbid conditions associated with Acute Coronary Syndrome. The most commonly prescribed drug classes for main indications in Acute Coronary Syndrome were anti-platelet drugs 600 (100\%) followed by antihypertensives (96.16\%), antihyperlipidemics (91.16\%). Extensive polypharmacy (9.68 drugs per prescription) was noticed in the prescriptions. The prescribing pattern can be improved by reducing the number of drugs per prescription. Many drugs $(61 \%)$ were prescribed by generic name. The economic burden of the patients can be reduced by prescribing more generic drugs.

Acknowledgment: I would like to acknowledge the Department of Medicine, Department of Pharmacology, Rural Medical College and Department of Record Section, Pravara Rural Hospital, Loni, for allowing us to conduct the present study.

\section{References}

1. Lloyd-Jones D, Adams R, Carnethon M, et al; American Heart Association Statistics Committee and Stroke Statistics Subcommittee. Heart disease and stroke statistics - 2009 update. a report from the American Heart Association Statistics Committee and Stroke Statistics
Subcommittee Circulation. 2009 Jan

27;119(3):480-486. Epub 2008 Dec 15

2. (Nichols M, Townsend N, Scarborough P, et al. Cardiovascular disease in Europe 2014: epidemiological update. Eur Heart J 2014;35:2929. 10.1093/eurheartj/ehu378

3. Reddy KS . Cardiovascular disease in nonWestern countries. N Engl J Med. 2004 Jun 10; 350(24):2438-40.

4. Okrainec K, Banerjee DK, Eisenberg MJ. Acute Coronary Syndromein the developing world. Am Heart J. 2004 Jul; 148(1):7-15.

5. Enas EA, Kannan S. How to beat the heart disease epidemic among South Asians. A prevention and management guide for Asian Indians and their doctors. Downers Grove: Advanced Heart Lipid Clinic USA, 2007. Indian Heart J 2008; 60: 161-175.

6. Acute Coronary Syndromes: Diagnosis and Management, Part I Amit Kumar, MD, and Christopher P. Cannon, MD, Mayo Clin Proc. • October 2009;84(10):917-938

7. Balady GJ, Williams MA, Ades PA, Bittner V, Comoss P, Foody JAM, et al. Core components of cardiac rehabilitation/secondary prevention programs. Circulation. 2007; 115: 26752682.

8. Beaglehole R, Epping-Jordan A, Patel V, Chopra M, Ebrahim S, Kidd M, Haines A. Improving the prevention and management of chronic disease in low-income and middle-income countries: a priority for primary health care. Lancet. 2008; 372: 940-949.

9. De Wilde S, Carey IM, Richards N, Whincup PH, Cook DG. Trends in secondary prevention of ischemic heart disease in the UK 1994-2005: use of individual and combination treatment. Heart. 2008; 94: 83-88.

10. Newby LK, LaPointe NMA, Chen AY, Kramer JM, Hammill BG, DeLong ER, et al. Long term adherence to evidence based 
secondary prevention therapies in coronary artery disease. Circulation. 2006; 113: 203-212.

11. Ramsay LE. Bridging the gap between clinical pharmacology and rational drug prescribing. Br J Clin Pharmacol. 1993; 35: 575-576.

12. Vries MD, Heluling RH, Hogerzeil HV, Freste DA. Guide to good prescribing. A practical guide W.H.O. 1994.

13. Pradhan SC, Shewade DG, Shashindren CH, Bapna IS. Drug utilization studies. National Med J India. 1988; 1: 185-189

14. World Health Organization. (1993). How to investigate drug use in health facilities: selected health use indicators. Geneva: 187. Available online at http://www.google.co.in/url?sa=t\&source= web\&cd $=2 \&$ ved $=0 \mathrm{CB} 8 \mathrm{QFj} A B \& u r l=$ http $\% 3 \mathrm{~A} \% 2 \mathrm{~F} \% 2 \mathrm{Farchives}$.who.int $\% 2$ Fprduc2 004\%2Frducd\%2FINRUD_2000_CDRO M\%2FManuals\%2FHow\%2520to\%2520I nvestigate\%2520Drug\%2520Use.pdf\&rct= $\mathrm{j} \& \mathrm{q}=$ World $\% 20$ Health\%20Organization $\%$ 2C\%20\%281993\%29\%2C\%20How\%20to $\% 20$ investigate $\% 20 \mathrm{drug} \% 20$ use $\% 20 \mathrm{in} \% 2$ Ohealth $\% 20$ facilities $\% 3 \mathrm{~A} \% 20$ selected $\% 20$ health $\% 20$ use $\% 20$ indicators\&ei=GHFbTf SIJY_BccyGza4K\&usg=AFQjCNFD8Qdn SliahUxtsOsObNf_L Jplrg\&cad=rja (accessed on 15th March, 2015)

15. Kamath A, Shanbhag T, Shenoy S, Ramesh S. A retrospective study of the drug prescribing pattern in acute myocardial infarction. Ind $\mathrm{J}$ Pharmacol. 2008; 40: S60- S61.

16. Tasneem $\mathrm{S}$ and Fouzia N. Drug utilization study in ischemic heart diseases associated with diabetes and hypertension. Int $\mathbf{J}$ Pharma and Bio Sci. 2010; 1(3): 1-4.

17. Jorg M, Giorgio N, Roger D, Christiane G, Felix G, Ferenc F. National survey on prescription of cardiovascular drugs among outpatients with Acute Coronary
Syndromein Switzerland. Swiss Med Wkly 2003; 133: 88-92.

18. Banerjee S, Kumar V, Ramachandran P, Kamath A. Does the pharmacological management of unstable angina vary with age and gender - a descriptive study. Journal of Clinical and Diagnostic Research. 2010; 4:3150-3157.

19. Datta S, Sharma C. Prescribing pattern of antihypertensives in patients having comorbid ischemic heart disease: Study in a tertiary care hospital. Journal of Pharmacy Research. 2010; 3: 2142-2144.

20. Sreedevi K, Rao VJ, Fareedullah MD, Vijayakumar S. A study on prescription pattern of statins in cardiovascular disease. Der Pharmacia Lettre, 2011; 3: 393-396. 